\title{
An elderly long-term care resident with crusted scabies
}

\author{
Matthew Sandre HBMSc BScN ${ }^{1}$, Filip Ralevski ART BSc ${ }^{2}$, Neil Rau MD FRCPC ${ }^{3,4}$
}

M Sandre, F Ralevski, N Rau. An elderly long-term care resident with crusted scabies. Can J Infect Dis Med Microbiol 2014;25(1):39-40.

Crusted scabies is a highly contagious form of scabies. Altered immune response, nutritional deficiencies and modified host response are all risk factors for crusted scabies. The authors report a case involving a patient found to have a chronic maculopapular, erythematous rash with large hyperkeratotic, white and grey plaques on the soles of both feet. An ultimate diagnosis of crusted scabies was reached after a delay in diagnosis suspected to be caused by the similarity in appearance to more common skin conditions such as psoriasis. After topical permethrin was unsuccessful, intermittent dosing of oral ivermectin resulted in a rapid reduction in cutaneous plaques.

Key Words: Crusted; Long-term care; Norwegian; Sarcoptes scabiei; Scabies

\section{CASE PRESENTATION}

A 94-year-old woman with progressive dementia over the previous year was transferred from a long-term care facility to hospital in late autumn, to address worsening confusion and hallucinations secondary to hypernatremia. In addition, the patient had a two-month history of a generalized, pruritic, erythematous skin rash, and a 'scaly rash' on the soles of both feet leading up to the present admission. At the time of onset, the rash was treated with $50 \mathrm{mg}$ oral prednisone, which was gradually tapered to $2.5 \mathrm{mg}$, in addition to oral hydroxyzine $10 \mathrm{mg}$ three times daily. Her medical history also included dementia, glaucoma, depression, osteoporosis and degenerative disc disease. She had no history of dermatological disease. When examined, the patient was observed to have a diffuse, maculopapular, erythematous rash across her truncal area and extremities. The scalp was xerotic, with grey crusts in the hair. On the soles of both feet, large, hyperkeratotic, white and grey plaques with fissures were noted (Figure 1). Leukocytosis (white blood cell count $11.5 \times 10^{9} / \mathrm{L}$ ) with eosinophilia $\left(1.9 \times 10^{9} / \mathrm{L}\right.$ ) were present on admission. A skin sample was obtained.

\section{DIAGNOSIS}

The skin scrapings were mounted on a slide with a drop of Euparal (Bioquip, USA) to act as a clearing agent, with permanent mounting media once dried. Compared with other mountants, Euparal is believed to offer better optical and drying properties (1). A study by Berlin and Miller (1) further discusses the use of Euparal and its clinical advantages and disadvantages. The slide was heated gently, and examined under the microscope at $250 \times$ magnification without any staining agent. A diagnosis of crusted scabies (also referred to as Norwegian scabies) was confirmed by the presence of Sarcoptes scabiei adult mites, as well as visible mite eggs. Another resident at the same long-term care facility was ultimately confirmed as having a scabies infestation using similar microbiological methods.

\section{Une éruption chez un résident âgé d'un centre de soins de longue durée}

La gale hyperkératosique est une forme de gale extrêmement contagieuse. Une détérioration de la réponse immunitaire, des carences nutritionnelles et une réponse modifiée de l'hôte en sont toutes des facteurs de risque. Les auteurs rendent compte d'un patient présentant une éruption maculopapuleuse et érythémateuse chronique comportant de grosses plaques hyperkératosiques blanches et grises sur la plante des deux pieds. Le diagnostic de gale hyperkératosique a été posé après un retard de diagnostic qu'on croit attribuable à sa similarité d'aspect avec des troubles cutanés plus courants, tels que le psoriasis. Après avoir essayé la perméthrine topique sans succès, une posologie intermittente d'ivermectine par voie orale a suscité la réduction rapide des plaques cutanées.

Topical daily treatments of $5 \%$ permethrin were started. After two weeks, no improvement was observed and a supply of oral ivermectin was ultimately obtained from Merck \& Co, Inc (USA) after obtaining authorization from the Health Canada Special Access Programme. Ivermectin treatment using an intermittent dosing regimen $(12 \mathrm{mg}$ or $200 \mu \mathrm{g} / \mathrm{kg}$ on days 1, 2, 8, 9 and 15) was administered. After seven days of treatment, near-complete resolution of the hyperkeratotic plaques was observed. The family elected to manage the patient in a palliative manner given her numerous comorbidities and poor functional status. She died in hospital from dehydration six days later.

\section{DISCUSSION}

Crusted scabies is a highly contagious form of scabies in which the patient can have a substantially higher mite load compared with traditional scabies infections (2). A review by Guldbakke and Khachemoune (3) summarized the risk factors for crusted scabies in three categories: altered immune response (eg, use of topical corticosteroids); nutritional deficiencies (eg, vitamin A deficiency); and modified host response (eg, Down syndrome) (3). Crusted scabies is often observed in older, debilitated or immunocompromised patients who have reduced ability to control the proliferation of the mites $(2,3)$. Cognitive impairment may also have an effect because of a resulting decreased ability to mechanically remove a portion of the mite load from scratching (3). A genetic predisposition to crusted scabies infection is suggested because as many as $40 \%$ of individuals infected have no discernable risk factors (2). Despite the higher mite load of crusted scabies, some patients do not experience an increase in pruritus above baseline (4). The plaque appearance of crusted scabies can be mistaken for psoriasis, potentially leading to a delay in diagnosis (5-7).

When topical therapies fail, oral ivermectin can be useful in the treatment of crusted scabies. Ivermectin is a macrocyclic lactonederived avermectin drug (8). The ability of ivermectin to selectively

\footnotetext{
${ }^{1}$ Michael G DeGroote School of Medicine, Hamilton; ${ }^{2}$ Public Health Ontario Laboratories, Toronto; ${ }^{3}$ Halton Healthcare Services, Oakville; ${ }^{4}$ University of Toronto School of Medicine, Toronto, Ontario

Correspondence: Dr Neil Rau, Halton Healthcare Services, Oakville-Trafalgar Memorial Hospital, 327 Reynold Street, Oakville, Ontario

L6J 3L7. Telephone 905-844-5346, fax 905-849-6551, e-mail nrau@haltonhealthcare.com
} 


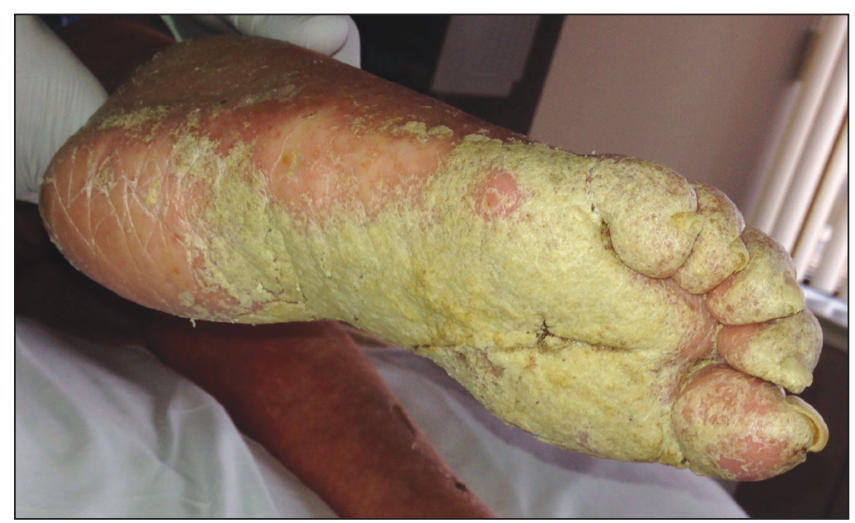

Figure 1) Hyperkeratotic plaques on patient's foot

interact with glutamate-gated chloride channels leads to an increase in permeability of the cell to chloride ions (8). This results in a decrease in neurotransmission to muscle cells, causing paralysis and, ultimately, death of the parasite (8).

This patient had a history of oral prednisone use, increasing her risk for presenting with this form of infection. Crusted scabies in individuals who have recently used topical or oral corticosteroids has been noted previously (9-11). Two of these cases discuss such an infection, or worsening of the infection after only topical corticosteroid use $(10,11)$. This is in contrast to the report by Binic et al (9), who describe a case of crusted scabies after the use of topical and oral corticosteroids. Another challenge with the use of corticosteroids for a patient with a scabies infection is the potential to mask the typical pruritus and inflammation, producing a rare, and difficult to recognize, entity known as scabies incognito (12). Thus, although the use of corticosteroids with scabicidal therapy is not contraindicated, we suggest an avoidance of use if possible. Oral antihistamines in place of corticosteroids have been used with success in conjunction with scabicidal therapy to control pruritus (12). Corticosteroids may have a role post-treatment in scabies infections. After successful treatment, the pruritus and changes in skin integrity may linger, appearing as

\section{REFERENCES}

1. Berlin OG, Miller MJ. Euparal as a permanent mounting medium for helminth eggs and proglottids. J Clin Microbiol 1980;12:700-3.

2. Roberts LJ, Huffam SE, Walton SF, Currie BJ. Crusted scabies: Clinical and immunological findings in seventy-eight patients and a review of the literature. J Infect 2005;50:375-81.

3. Guldbakke KK, Khachemoune A. Crusted scabies: A clinical review. J Drugs Dermatol 2006;5:221-7.

4. Kolar KA, Rapini RP. Crusted (Norwegian) scabies. Am Fam Physician 1991;44:1317-21.

5. Costa JB, Rocha de Sousa VL, da Trindade Neto PB, Paulo Filho Tde A, Cabral VC, Pinheiro PM. Norwegian scabies mimicking rupioid psoriasis. An Bras Dermatol 2012;87:910-3.

6. Fonseca V, Price HN, Jeffries M, Alder SL, Hansen RC.

Crusted scabies misdiagnosed as erythrodermic psoriasis in a 3-year-old girl with Down syndrome. Pediatr Dermatol 2013 October 21 (Epub ahead of print).

7. Goyal NN, Wong GA. Psoriasis or crusted scabies. Clin Exp Dermatol 2008;33:211-2.

8. Geary TG. Ivermectin 20 years on: Maturation of a wonder drug. Trends Parasitol 2005;21:530-2. postscabies eczema (13). It is recommended at this later state to rehydrate the skin with moisturizers and to control the inflammation with strong corticosteroids (13).

Our patient also had eosinophilia, which was observed in $58 \%$ of 78 patients with crusted scabies in one study (2). Twelve percent of these patients had a very high eosinophil count $\left(>7.0 \times 10^{9} / \mathrm{L}\right)(2)$. Eosinophilia is observed more often in those with crusted scabies compared with the noncrusted form, supporting the theory that separate host immune responses account for the different appearances between these clinical presentations (2,14-16).

The dermatological presentation in this patient led to a long list of differential diagnoses including psoriasis. Previous case studies also refer to the similar appearance of psoriasis and crusted scabies (5-7). Interestingly, the affected area of the body varied among these studies, ranging from involvement of only the feet or fingertips, to a more generalized presentation on multiple areas of the body (5-7). Notable in these cases is that the presence of hyperkeratotic plaques led to crusted scabies being mistaken for psoriatic skin disease, with a concomitant delay in diagnosis (5-7). A subsequent similar case at the same institution gave rise to a hospital-wide outbreak due to a delayed recognition of the diagnosis.

To achieve more timely treatment, we recommend that physicians add the diagnosis of crusted scabies to their differential when a patient presents with a cutaneous eruption that includes a component of hyperkeratotic plaques. Although not contraindicated, the avoidance of corticosteroid usage during an active scabies infection is advisable to prevent further difficulty in diagnosis and increase risk for crusted scabies. Additionally, if no response is observed with topical permethrin, oral ivermectin appears to successfully cause a rapid reduction in signs of crusted scabies.

ACKNOWLEDGEMENTS: The authors thank Dr Andrea Boggild and the Public Health Ontario Laboratory for providing technical expertise and assistance in the review of the microscopy slides and manuscript.

\section{SOURCES OF FUNDING: None.}

DISCLOSURES: The authors have no conflicts of interest to declare.
9. Binic I, Jankovic A, Jovanovic D, Ljubenovic M. Crusted (Norwegian) scabies following systemic and topical corticosteroid therapy. J Korean Med Sci 2010;25:188-91.

10. Chan CC, Lin SJ, Chan YC, Liao YH. Clinical images: Infestation by Norwegian scabies. CMAJ 2009;181:289.

11. Jaramillo-Ayerbe F, Berrio-Munoz J. Ivermectin for crusted Norwegian scabies induced by use of topical steroids. Arch Dermatol 1998;134:143-5.

12. Kim KJ, Roh KH, Choi JH, Sung KJ, Moon KC, Koh JK. Scabies incognito presenting as urticaria pigmentosa in an infant. Pediatr Dermatol 2002;19:409-11.

13. Hengge UR, Currie BJ, Jager G, Lupi O, Schwartz RA. Scabies: A ubiquitous neglected skin disease. Lancet Infect Dis 2006;6:769-79.

14. Glover A, Young L, Goltz AW. Norwegian scabies in acquired immunodeficiency syndrome: Report of a case resulting in death from associated sepsis. J Am Acad Dermatol 1987;16(2 Pt 1):396-9.

15. Falk ES, Eide TJ. Histologic and clinical findings in human scabies. Int J Dermatol 1981;20:600-5.

16. Walton SF. The immunology of susceptibility and resistance to scabies. Parasite Immunol 2010;32:532-40. 


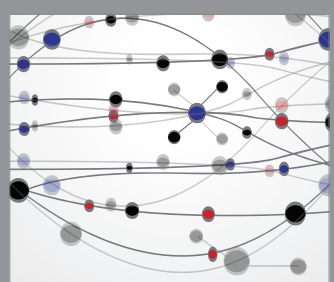

The Scientific World Journal
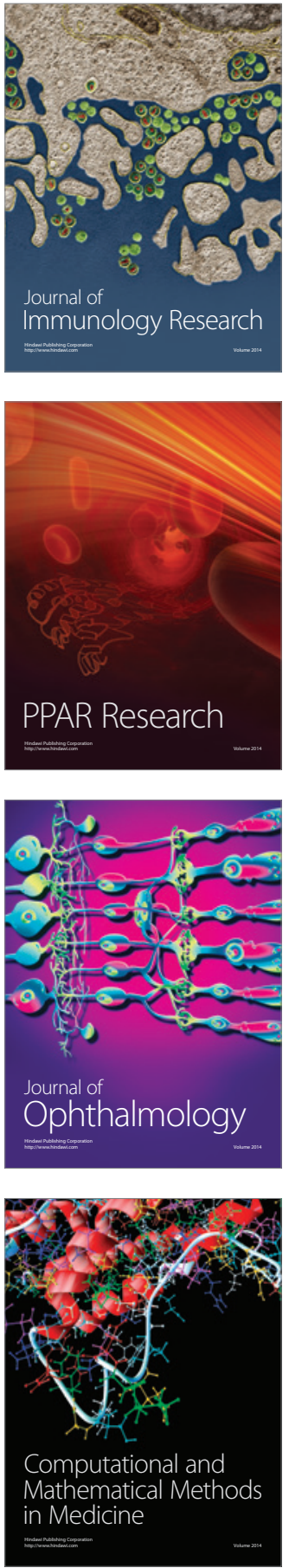

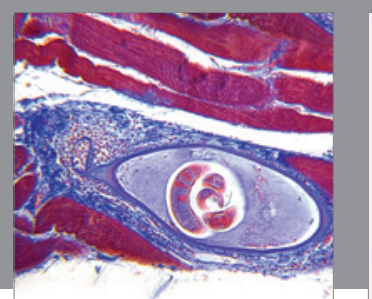

Gastroenterology Research and Practice

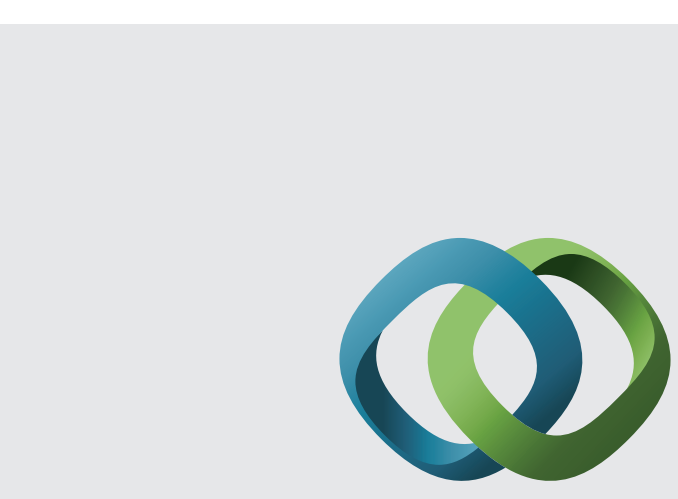

\section{Hindawi}

Submit your manuscripts at

http://www.hindawi.com
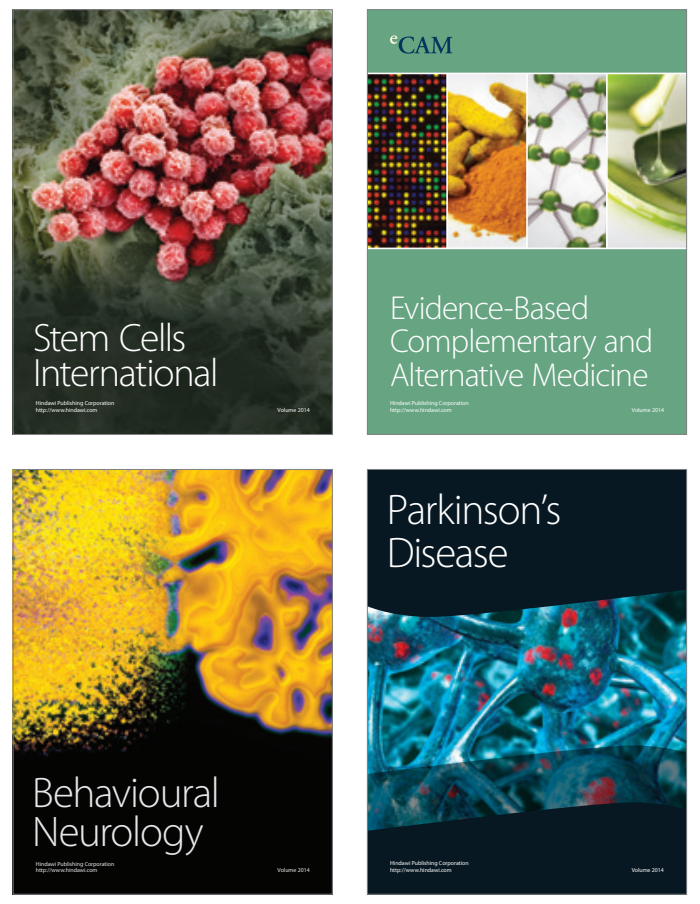
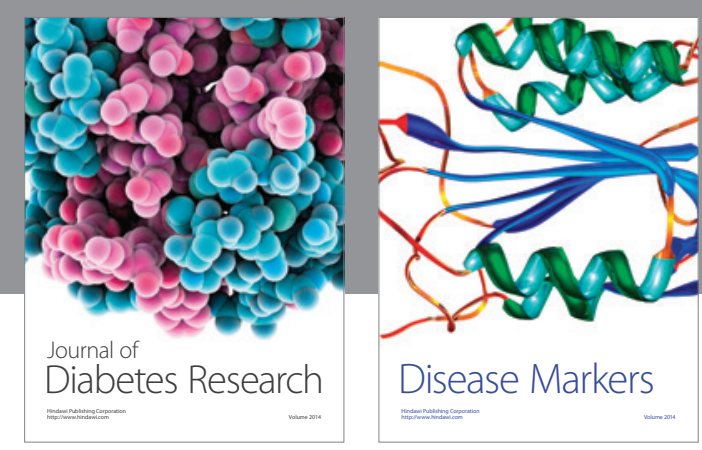

Disease Markers
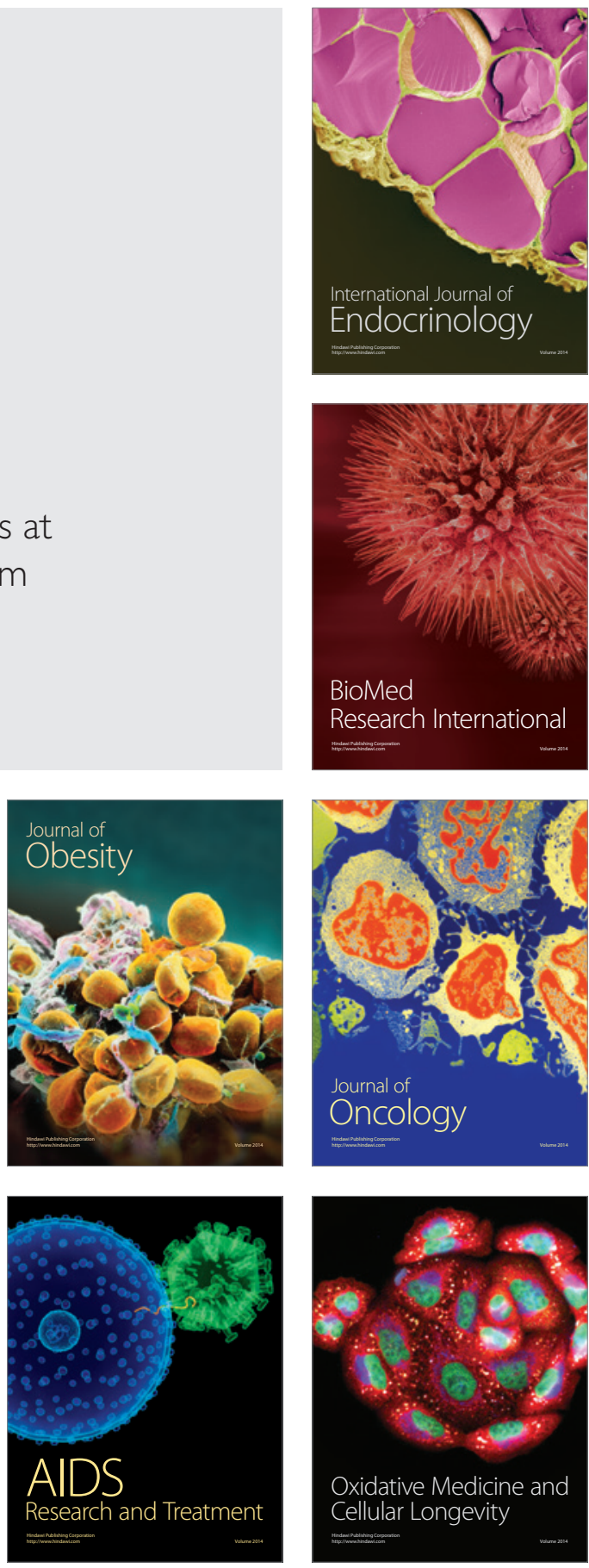